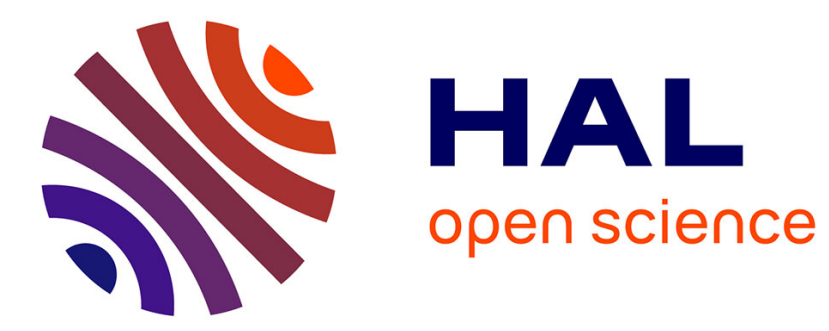

\title{
Sodium-tolerant matrix for matrix-assisted laser desorption/ionization mass spectrometry and post-source decay of oligonucleotides
}

Hélène Lavanant, Catherine M. Lange

\section{- To cite this version:}

Hélène Lavanant, Catherine M. Lange. Sodium-tolerant matrix for matrix-assisted laser desorption/ionization mass spectrometry and post-source decay of oligonucleotides. Rapid Communications in Mass Spectrometry, 2002, 16 (20), pp.1928-1933. 10.1002/rcm.816 . hal-02351795

HAL Id: hal-02351795

https://hal-normandie-univ.archives-ouvertes.fr/hal-02351795

Submitted on 6 Nov 2019

HAL is a multi-disciplinary open access archive for the deposit and dissemination of scientific research documents, whether they are published or not. The documents may come from teaching and research institutions in France or abroad, or from public or private research centers.
L'archive ouverte pluridisciplinaire HAL, est destinée au dépôt et à la diffusion de documents scientifiques de niveau recherche, publiés ou non, émanant des établissements d'enseignement et de recherche français ou étrangers, des laboratoires publics ou privés. 


\title{
Sodium Tolerant Matrix for Matrix-Assisted Laser Desorption / Ionization Mass Spectrometry and Post Source Decay of Oligonucleotides
}

Hélène Lavanant, Catherine Lange

Laboratoire de Spectrométrie de Masse Bio-Organique, CNRS-UMR 6014, INSERM-IFR 23, UFR des Sciences et Techniques de Rouen, 76821 Mont St Aignan Cedex, France

\begin{abstract}
A mixture of 2',4',6'-trihydroxyacetophenone in acetonitrile and aqueous triammonium citrate solution in a 1:1 molar proportion ( $0.2 \mathrm{M}$ concentration) was found to be a good matrix for the detection of synthetic oligodeoxynucleotide samples. A high proportion of volatile solvent as well as the high salt content ensures fast co-crystallization of the matrix, co-matrix and analyte molecules. MALDI mass spectra obtained in negative ion reflectron mode from samples prepared with this protocol show deprotonated molecules $[\mathrm{M}-\mathrm{H}]^{-}$, rather than sodium adducts as the most abundant ion even when up to $50 \mathrm{mM}$ of sodium chloride is present in the sample. The matrix is shown to be effective for low mass modified single nucleotides as well as for longer oligodeoxynucleotides (up to 18mer). PSD mass spectra can also be obtained by increasing the laser fluence. Simple sequence information such as the identity and localization of a deleted base or the $5^{\prime} / 3^{\prime}$ orientation can then easily be obtained. The calibration method and mass accuracy required is discussed depending on the type of information aimed at.
\end{abstract}

Corresponding author : Hélène Lavanant, Laboratoire de Spectrométrie de Masse Bio-Organique, CNRSUMR 6014, INSERM-IFR 23, UFR des Sciences et Techniques, Université de Rouen, 76821 Mont St Aignan Cedex, France. E-mail : helene.lavanant@univ-rouen.fr 


\section{Introduction}

With the growth of proteome research, matrix-assisted laser desorption/ionization (MALDI) and post source decay (PSD) mass spectrometry (MS) has become widely used as a means to obtain mass and sequence information for proteins and peptides. This popularity arises from the numerous advantages of the technique. Among which are (i) its ease of use, (ii) that it can be easily automated with low risk of cross contamination between samples through the use of separate targets for each sample, and (iii) that the spectra are easily interpreted with mostly singly charged ions present. Although these advantages hold for DNA samples as well, use of MALDI for the analysis of nucleic acids is far less widespread than for other biomolecules ${ }^{1-3}$.

The competition with well established automated high throughput devices using enzymatic and chemical cleavage methods ${ }^{4}$ is partly responsible for this state of things. Another reason is that the presence of metal adducts, particurlarly with sodium cations, with these highly polar polyanionic molecules dramatically reduces the sensitivity and mass accuracy both in MALDI and electrospray (ESI) mass spectra. As a result, sample preparation that eliminates or minimizes metal cations is crucial and a variety of methods have been studied and tested for this purpose ${ }^{5-10}$. Cation exchange resin beads ${ }^{5,6}$, comatrices $^{7,8}$, C18 purification tips, anion exchange HPLC, desalting columns ${ }^{9}$, and minidialysis have been tested by J. A. Ragas et al. ${ }^{10}$ who found the most efficient method was purification with micropipet tips packed with C18 reversed-phase packing material (e.g. Zip tips). In some cases however, poor analyte recoveries limited the effectiveness of the technique.

It is well known that the matrix plays an important role in the desorption/ionization process of MALDI. The matrices used for oligodeoxynucleotides (ODN) are different than the ones commonly used for peptides and proteins. The most popular one was 3-hydroxypicolinic acid (3HPA) for a long time ${ }^{11}$. The neutral 6-aza-2-thiothymine (ATT) is also used particularly as it allows the detection of doubled-stranded DNA by UV-MALDI ${ }^{12-14}$. L. K. Zhang et $a l .{ }^{15}$ found that a 2:1:0.003 mixture of anthranilic acid (AA), nicotinic acid (NA) and diammonium citrate was optimal compared to other proportions of these acids. Mass spectra obtained in these conditions requires lower laser power while yielding higher analyte signal intensities and resolution. 2',4',6'-trihydroxyacetophenone (2,4,6-THAP) and 2',3',4'trihydroxyacetophenone (2,3,4-THAP) have also been used, in various proportions, but not as extensively 
although several authors have found it most efficient ${ }^{16,17}$. Ferulic acid with an addition of fructose $(6 \mathrm{mg} / \mathrm{mL}$, overlayer concentration) to suppress fragmentation was also suggested as an adequate matrix for DNA analysis ${ }^{17}$.

One common feature in sample preparation protocols with acid matrices is that high proportions of water are used in the solvent. A $50 \%$ water proportion is usually required to insure the $0.2 \mathrm{M}$ (or so) concentration generally required for MALDI. After the aqueous oligonucleotide solution is added, the proportion of water often amounts up to $75 \%$ or more. This high proportion considerably slows down the drying and co-crystallization processes resulting in large crystals, inhomogeneous targets which cause poor resolution and spot-to-spot reproducibility ${ }^{18}$. The use of matrix additives which are aqueous solutions of ammonium salts also contribute to high proportions of water and sometimes cocrystallization cannot be achieved. Fast evaporation-overlayer sample preparation ${ }^{17}$ was shown to be effective to obtain homogenous crystallization, but that involves longer preparation tasks and some agility for the multiple deposits.

Even then, acid matrices often have to be purified and/or recrystallized as they can contain some amounts of sodium salts. In contrast, trihydroxyacetophenone is likely to be less contaminated with sodium and is soluble in pure methanol and acetonitrile.

We wish to report here the results obtained using a renewed combination of THAP matrice and triammonium citrate matrix additive. Our protocol minimizes water proportion in the deposit and thus allows fast co-crystallization of matrix, additive and analyte molecules while suppressing metal adducts in ODN samples. This is achieved by using 2,4,6-THAP and 2,3,4-THAP in pure acetonitrile and highly concentrated aqueous triammonium citrate solutions as co-matrix. Although these matrices and additives have been used before, this novel combination was found very effective as it yielded intense signal in a delayed extraction reflectron time of flight analyses even with when high concentrations of sodium cation are present in the sample. Moreover, PSD mass spectra on the same targets showed intense fragment ions when an increased laser fluence was applied. We illustrate here with several examples how the combined information may be used to obtain or confirm base composition, $5^{\prime} / 3^{\prime}$ orientation, and identify as well as localize a single nucleotide deletion in low molecular weight synthesized ODNs. 


\section{Experimental section}

\section{Materials}

dT 10 , dGCTA (4mer, 1173.3 Da ), dGTATTAT (7mer, 2110.5 Da), dGCTCAGAGC (10mer1, 3028.0

Da), and complementary dCGAGACTCG (10mer2, $3028.0 \mathrm{Da})$ were purchased with reverse phase purification from Sigma-Genosys LTd (Pampisford, UK). dpT 18 (5493.5 Da), dpC 10 (2909.9 Da) and $\mathrm{dpC}_{15}(4355.8 \mathrm{Da})$ were purchased as ammonium salts from Sigma Aldrich (St Quentin Fallavier, France). $0.1 \mathrm{mM}$ aliquots were prepared using HPLC grade water and used without further purification.

2,3,4-THAP and 2,4,6-THAP, monohydrate, and triammonium citrate were purchased from Sigma Aldrich (St Quentin Fallavier, France) and used as received. All solvents were HPLC grade.

The modified single base nucleotides, named A', C' and T', were amiably provided as disodium salts by the LFAOC (Laboratoire des Fonctions Azotées et Oxygénées Complexes), University of Rouen, France.

\section{Instrumentation}

All mass spectra were acquired on a TofSpec-E MALDI TOF instrument (Micromass, Manchester, UK) equipped with a UV nitrogen laser (337 nm, 4 ns laser pulse). It was used in negative ion reflectron mode. The acceleration voltage was set to $20 \mathrm{kV}$. Delayed extraction was optimized around $10 \mathrm{~ns}$. Laser fluence was attenuated to a value around $60 \mathrm{~mJ} . \mathrm{cm}^{-2}$. PSD analyses were obtained by increasing the laser fluence to $100 \mathrm{~mJ} . \mathrm{cm}^{-2}$ and gradually stepping down the voltage on the electrostatic mirror (four steps: $26000 \mathrm{~V}$, $19500 \mathrm{~V}, 14625 \mathrm{~V}$, and $10969 \mathrm{~V})$ while the acceleration voltage is maintained constant $(20 \mathrm{kV})$.

Mass axis calibration in the parent ion mode was obtained with a mixture of 3 ODNs (usually 4mer, $\mathrm{dpC}_{15}$, and $\left.\mathrm{dpT}_{18}\right)$. In the PSD mode, $\mathrm{dT}_{10}$ was used as calibrant at the first three different reflectron voltages; the absence of small fragment ions impeded the calibration in the lower mass range. 


\section{Sample preparation}

2,4,6-THAP and 2,3,4-THAP solutions were prepared separately each day with a $0.2 \mathrm{M}$ concentration in pure acetonitrile; triammonium citrate solutions were $0.2 \mathrm{M}$ in ultrapure water. A small volume of ODN solutions (usually $2 \mu \mathrm{L}$ of $10^{-4} \mathrm{M}$ to $5.10^{-8} \mathrm{M}$ ) were mixed with the matrix and triammonium citrate solutions in a 1:1:1 v/v/v proportion. The matrix solution was often pure 2,4,6-THAP or a $1: 1 \mathrm{v} / \mathrm{v}$ proportion of the two compounds.

1 to $2 \mu \mathrm{L}$ of the mixture was deposited on the targets and vacuum dried, the $33 \%$ acetonitrile proportion and high salt concentration enabling fast co-crystallisation of the matrix, co-matrix and analyte molecules.

\section{Results and Discussion}

\section{Sensitivity and salt contamination}

Zhu et al. ${ }^{16}$ tested various proportions and combinations of THAP matrice with and without ammonium citrate in the negative ion mode and concluded a 2/1/1 v/v/v proportion of 2,4,6-THAP (0.2 M), 2,3,4THAP $(0.2 \mathrm{M})$ and $0.3 \mathrm{M}$ ammonium citrate as the best proportion for the detection of DNA. Consistently with their report, we find a lower signal intensity for deprotonated $[\mathrm{M}-\mathrm{H}]^{-}$ions with $2,3,4$ THAP than with 2,4,6-THAP, the latter giving larger proportions of doubly charged ions $[\mathrm{M}-2 \mathrm{H}]^{2-}$. Contrary to what is previously reported, however, we do not observe any significant prompt fragmentation with 2,4,6-THAP alone (in combination with triammonium citrate). In most cases, we therefore used pure 2,4,6-THAP in acetonitrile without any 2,3,4-THAP.

With a 1:1 molar proportion of 2,4,6-THAP and triammonium citrate, we found, as is usual, that sensitivity is highly dependent on the sample. T-rich ODNs, such as $\mathrm{dT}_{10}$ and $\mathrm{dpT}_{18}$ give the lowest detection limits. On Figure 1a is shown the signal obtained for $10 \mathrm{fmol}$ of $\mathrm{dpT}_{18}$ in negative ion reflectron mode. The signal-to-noise $(\mathrm{S} / \mathrm{N})$ from the deprotonated ion $\left[\mathrm{dpT}_{18}-\mathrm{H}\right]^{-}$is 30 , suggesting a detection limit in the low fmol range. The signal for 1 pmol of 10 mer1, however, is much lower, with a S/N of 8 (Figure 1b). A quantity of 1 to $10 \mathrm{pmol}$ was found to give adequate signal for all the samples tested. 


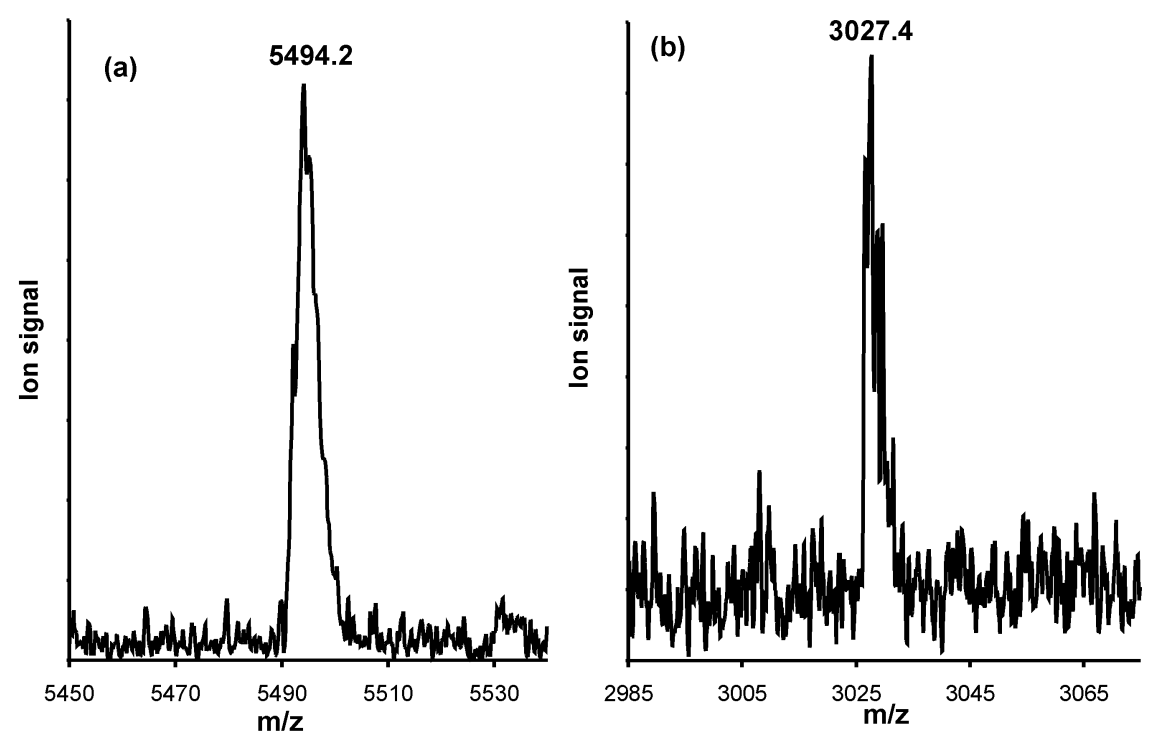

Figure 1. Negative ion MALDI of (a) $100 \mathrm{fmol}$ of dpT18, (b) 1 pmol of 10mer1, deposited on target. The samples were prepared with $1: 1$ molar ratio of 2,4,6-THAP and triammonium citrate in water/acetonitrile $1 / 1 \mathrm{v} / \mathrm{v}$. The figures represent raw data, resulting from the sum of 10 laser shots.

Although this is lower than what has previously been reported on similar samples ${ }^{15,17}$, one advantage of our protocol is its tolerance to salt contamination. To emphasize this, we tested the effect of the presence of sodium cations by adding aqueous solutions of sodium chloride in different concentrations to a $10^{-5} \mathrm{M}$ solution of $\mathrm{dT}_{10}(1 / 1 \mathrm{v} / \mathrm{v})$. The ODN and sodium chloride solutions were then allowed to stand for 2 hours at room temperature before preparing the targets as described. The spectra recorded on the targets prepared with these solutions following our protocol are shown on Figure 2. In all cases, the deprotonated molecule $[\mathrm{M}-\mathrm{H}]^{-}$is the most intense signal obtained from the ODN, although, expectedly its intensity decreases when higher amounts of sodium are present. A significant amount of sodium adduct $[\mathrm{M}+\mathrm{Na}-\mathrm{H}]^{-}$is observed only when an $0.1 \mathrm{M}$ solution of $\mathrm{NaCl}$ is added (Figure 2a). This corresponds to $33 \mathrm{nmol}$ of $\mathrm{NaCl}$ deposited which is $10^{4}$ times more then the amount of ODN on the target, and just 4 times less than the amount of matrix and co-matrix respectively.

This protocol was also tested on modified single base nucleotides (Figure 3), in the form of disodium salts. For these samples, the low mass part of the spectrum is simple enough to allow clear determination of the mass of the modified nucleotides from the deprotonated molecules $\left[\mathrm{A}^{\prime}-\mathrm{H}\right]^{-}$at $m / z, 380,\left[\mathrm{C}^{\prime}-\mathrm{H}^{-}\right.$ 
at $m / z 356$ and $\left[\mathrm{T}^{\prime}-\mathrm{H}\right]^{-}$at $m / z$ 371. The other peaks in the mass spectrum can be attributed to the matrix and/or comatrix : $m / z 167$ can be attributed to deprotonated THAP, $m / z, 191$ to citrate, $m / z, 335$ to a THAP dimer, and $m / z 405$ to sodiated citrate dimer. The latter peak demonstrates that the ammonium citrate comatrix contributes to the exchange of the sodium cation in the modified base, thus enabling the deprotonated modified nucleotide to be observed.
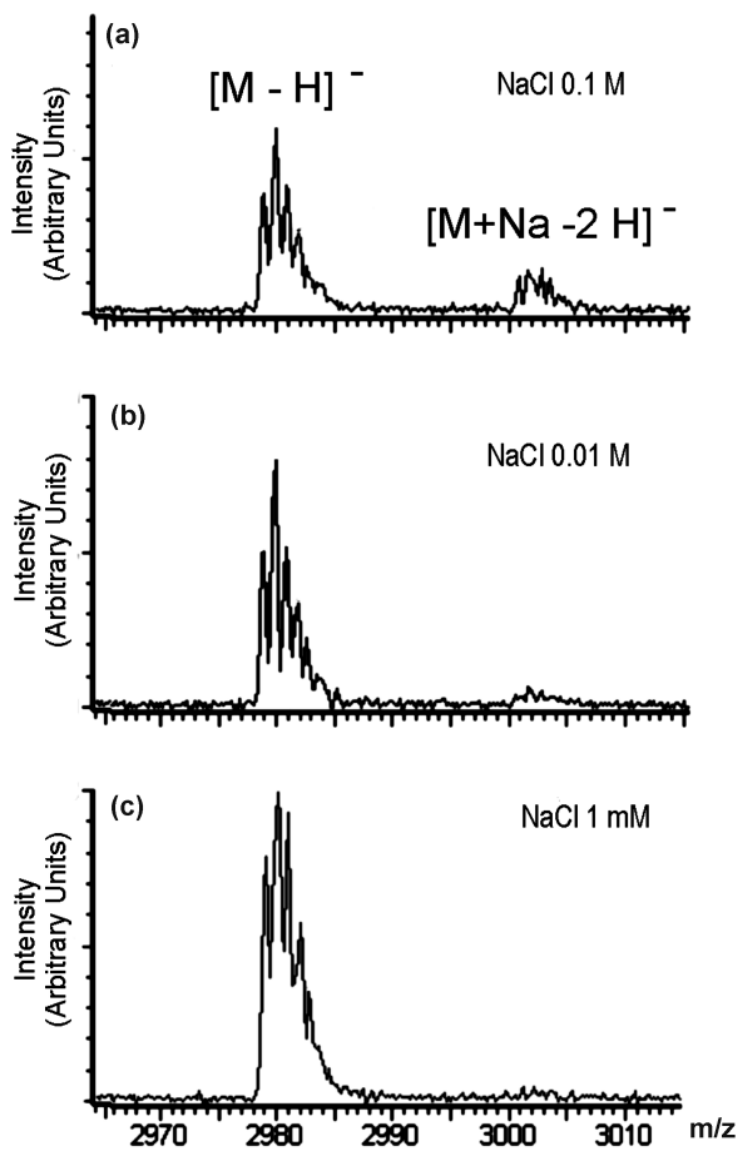

Figure 2. Negative ion MALDI mass spectra of $\mathrm{dT}_{10}$ with various amounts of sodium chloride. The spectra were obtained with a 1/1 molar ratio of 2,4,6-THAP in acetonitrile and aqueous triammonium citrate. A $10^{-5} \mathrm{M}$ solution of $\mathrm{dT}_{10}$ was mixed with an aqueous solution of sodium chloride [(a ) $0.1 \mathrm{M}$, (b) $0.01 \mathrm{M}$ and (c) $1 \mathrm{mM}$ as indicated] 2 hours prior the analysis, when it was mixed with the matrix and comatrix. $2 \mu \mathrm{l}$ was deposited on the target. The spectra shown are all the result of one laser shot. The intensity is normalized to the one measured on (c) $(\mathrm{NaCl} 1 \mathrm{mM})$. 


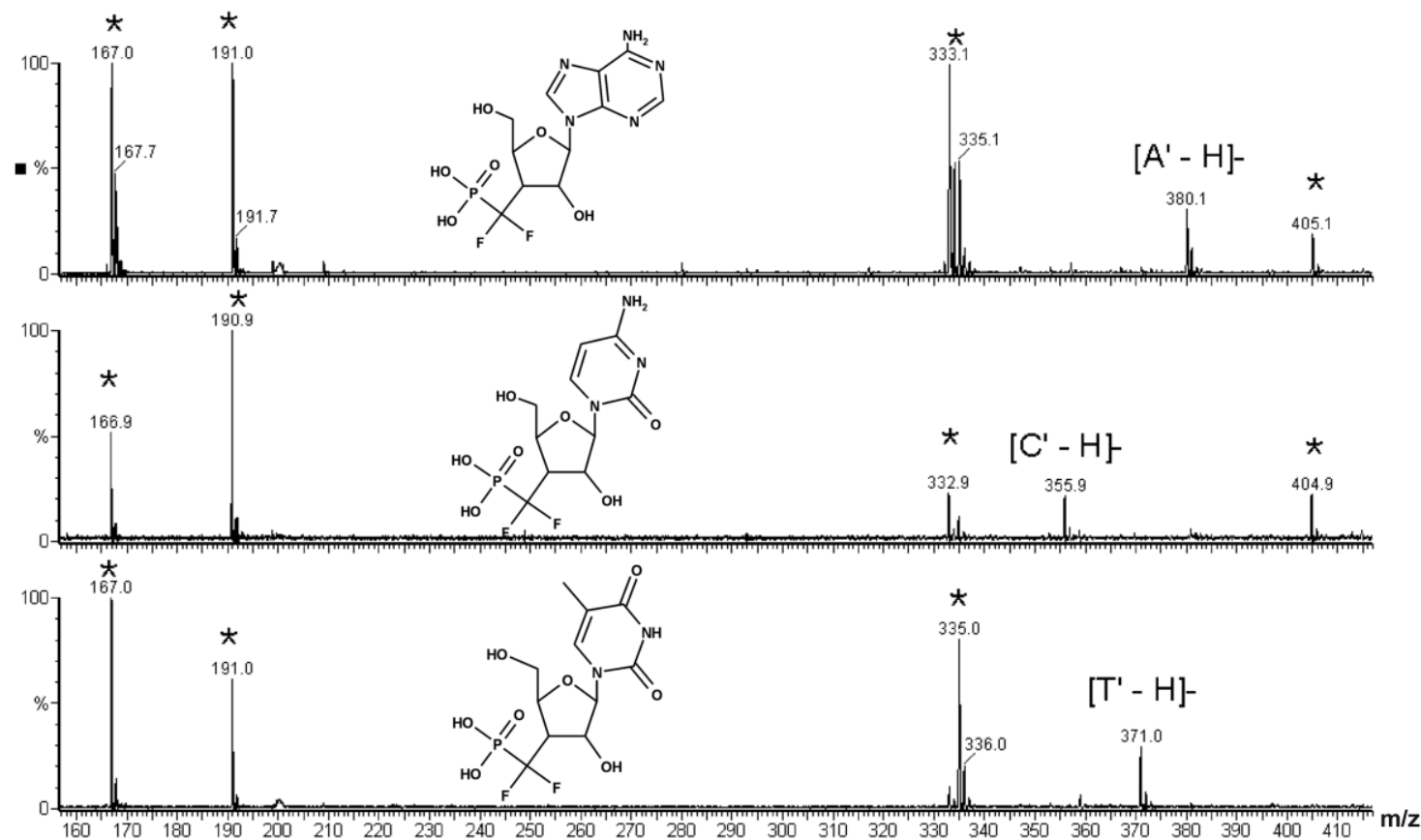

Figure 3. Negative ion MALDI mass spectra of low mass modified single nucleotides. The peaks with an asterisk arise from the matrix and co-matrix.

\section{Mass accuracy}

Mass accuracy in MALDI is highly dependent on the initial space and velocity distributions imparted to the ions during the desorption/ionization process. In order to obtain a good mass accuracy, the calibrant ions must be ejected with a space and velocity distribution similar that of the analyte ions, which will translate on the mass spectra into peaks with similar shapes and intensities. This is difficult to obtain from different targets and therefore, when using external calibration mass discrepancies of up to 1 or 2 Da can occur. An internal calibration lowers mass discrepancies to less than $1 \mathrm{Da}$, but 0.5 to $0.8 \mathrm{Da}$ errors can still happen if the mass difference or the intensities of the calibrants and analyte ions are too dissimilar . Although this kind of mass accuracy may look rather low $(0.05 \%$ to $0.01 \%$ at $\mathrm{m} / \mathrm{z} 2000)$, in some cases it may be sufficient to obtain the information which is sought.

When analyzing a "ladder" mixture of ODNs, such as one generated by enzymatic digestion or the products of automatic syntheses where failure sequences might be present, mass calibration with 1 or 2 Da shifts are not a problem since one only needs to distinguish mass differences of $289 \mathrm{u}(\mathrm{C}), 304 \mathrm{u}(\mathrm{T})$, 
$313 \mathrm{u}(\mathrm{A})$ and $329 \mathrm{u}(\mathrm{G})$; furthermore mass accuracy on mass differences are usually higher than on "absolute" masses. On Figure 4 is represented the negative ion reflectron mass spectrum of a 7 mer where a significant amount of deletion has occurred. The mass difference clearly shows that a deoxyadenosine is deleted.

When seeking the base composition of short ODNs, a computation of possible combinations of the four bases yielding a given mass with a \pm 2 Da tolerance can narrow the problem to less than five or six possibilities for 10 mers if the termination type is known. An example of such computation is given on Table 1 for 10 mer1. Note that by using a mass calibration with internal calibrants the error is decreased to less than 0.9 Da, and one further eliminates a number of sequences which generate a $1 \mathrm{Da}$ mass difference (such as AT/CG double substitutions or $\mathrm{GCT} / \mathrm{A}_{3}$ triple substitutions). The ambiguities that remain need a mass accuracy in the order of 0.01 Da which is difficult to obtain with time of flight analysis even with an internal calibration. PSD analysis is then needed to clear ambiguities.

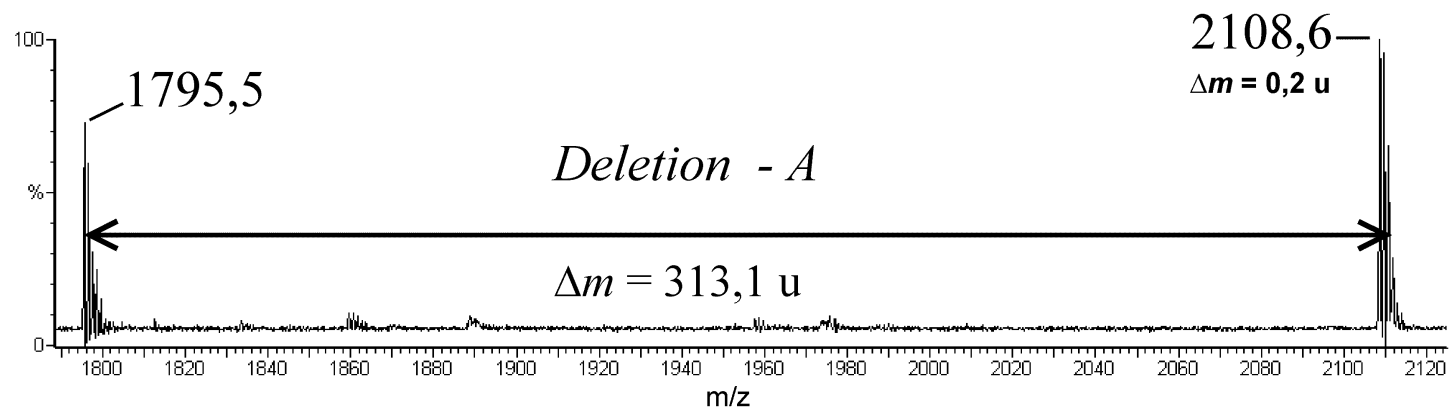

Figure 4. Negative ion MALDI mass spectrum of 7 mer (1/1 molar ratio of 2,4,6-THAP and triammonium citrate, and a $10 \mathrm{pmoL} / \mu \mathrm{L}$ solution of $\mathrm{ODN})$. 
Table 1. Possible compositions that may be attributed to $m / z, 3026.5 \pm 2 \mathrm{Da}$ (monoisotopic mass).

\begin{tabular}{|c|c|c|c|c|c|c|c|}
\hline Mass & Deviation & \multirow[t]{2}{*}{ A C } & \multirow[t]{2}{*}{$\mathrm{C}$} & \multirow[t]{2}{*}{$T$} & \multicolumn{2}{|r|}{ Length } & \multirow{2}{*}{$\begin{array}{c}\text { 5', 3' Terminations } \\
4 \text { combinations }\end{array}$} \\
\hline Tolera & $\pm 0.9 \mathrm{Da}$ & & & & & & \\
\hline 3026.5482 & 0.0000 & 2 & 3 & 3 & 2 & 10 & $\mathrm{OH} . \mathrm{OH}$ \\
\hline 3026.5859 & 0.0377 & 7 & 1 & 0 & 2 & 10 & $\mathrm{OH} . \mathrm{OH}$ \\
\hline 3026.5022 & -0.0460 & 2 & 5 & 1 & 2 & 10 & $\mathrm{OH} . \mathrm{p}$ \\
\hline 3026.5148 & -0.0334 & 4 & 5 & 1 & 0 & 10 & cyclic \\
\hline \multicolumn{2}{|c|}{ Tolerance $\pm 1.1 \mathrm{Da}$} & & & & & & 10 combinations \\
\hline 3027.5812 & 1.0330 & 6 & 2 & 1 & 1 & 10 & $\mathrm{OH} . \mathrm{OH}$ \\
\hline 3027.5435 & 0.9953 & 1 & 4 & 4 & 1 & 10 & $\mathrm{OH} . \mathrm{OH}$ \\
\hline 3025.5530 & -0.9952 & 3 & 2 & 2 & 3 & 10 & $\mathrm{OH} . \mathrm{OH}$ \\
\hline 3025.5070 & -1.0412 & 3 & 4 & 0 & 3 & 10 & $\mathrm{OH} . \mathrm{p}$ \\
\hline 3027.4975 & 0.9493 & 1 & 6 & 2 & 1 & 10 & $\mathrm{OH} . \mathrm{p}$ \\
\hline 3027.4598 & 0.9116 & 2 & 0 & 7 & 0 & 9 & p. p \\
\hline 3027.4515 & 0.9033 & 1 & 8 & 0 & 1 & 10 & p. p \\
\hline 3025.5196 & -1.0286 & 5 & 4 & 0 & 1 & 10 & cyclic \\
\hline 3025.4818 & -1.0664 & 0 & 6 & 3 & 1 & 10 & cyclic \\
\hline 3025.4607 & -1.0875 & 0 & 1 & 0 & 9 & 10 & cyclic \\
\hline \multicolumn{2}{|c|}{ Tolerance $\pm 2.0 \mathrm{Da}$} & & & & & & 5 combinations \\
\hline 3024.5577 & -1.9905 & 4 & 1 & 1 & 4 & 10 & $\mathrm{OH} . \mathrm{OH}$ \\
\hline 3028.4716 & 1.9234 & 0 & 2 & 0 & 8 & 10 & $\mathrm{OH} . \mathrm{p}$ \\
\hline 3028.4927 & 1.9445 & 0 & 7 & 3 & 0 & 10 & $\mathrm{OH} . \mathrm{p}$ \\
\hline 3028.4468 & 1.8986 & 0 & 9 & 1 & 0 & 10 & p. p \\
\hline 3028.4842 & 1.9360 & 2 & 2 & 0 & 6 & 10 & cyclic \\
\hline
\end{tabular}




\section{PSD analyses}

Although fragmentation is not desirable when one wants to obtain sensitive measurement of a molecular ion, it becomes valuable when sequence or other structural information is needed and it is then convenient to be able to carry out PSD analysis on the same target. This is readily achievable with 2,4,6-THAP with triammonium citrate co-matrix by increasing the laser fluence from roughly 60 to $100 \mathrm{~mJ} . \mathrm{cm}^{-2}$. As Kaufmann et al. ${ }^{19}$ pointed out, delayed extraction was also switched off to obtain maximum sensitivity for metastable decay. PSD observed in these conditions yields mostly high mass w-sequence ions (nomenclature by McLuckey et al. ${ }^{20}$ ) which brings information on the first bases at the 5 ' terminus. On Figure 5, the PSD mass spectra of the 7mer and the A-deleted component shows $\mathrm{w}_{6}{ }^{-}$and $\mathrm{w}_{4}^{-}$ions as corresponding to the most intense peaks. The signal corresponding to $\mathrm{W}_{5}^{-}$is very weak consistent with previous observation of lower fragmentation of phosphodiester bonds adjacent to a T-base ${ }^{3}$. Comparison of the two mass spectra clearly identifies deoxyadenosine from position 6 to be the one that is deleted in the GCATTAT sequence given for the 7mer (Table 2), as $\mathrm{w}_{4}{ }^{-}$appears with a 313 Da mass shift.
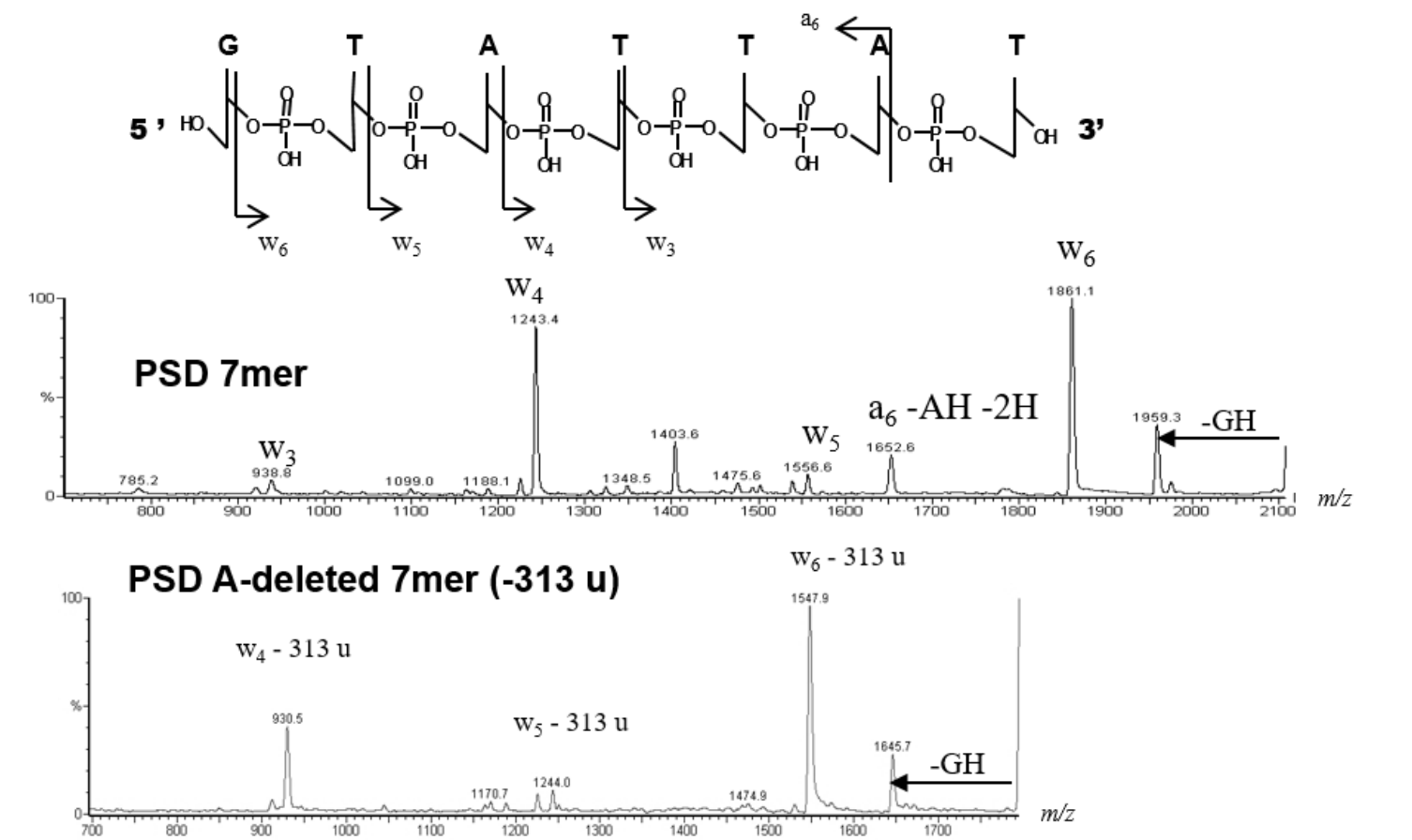

Figure 5. Negative ion MALDI PSD mass spectra of 7mer and its A-deleted component (1/1 molar ratio of 2,4,6-THAP and triammonium citrate, and a $10 \mathrm{pmoL} / \mu \mathrm{L}$ solution of ODN). 
Among other possible applications of PSD analyses, Figure 6 shows how the 5'/3' orientation of a 10mer ODN can be determined. ODNs 10 mer1 and 10 mer2 are isomers and both have a sequence CGAGATCTCG which differ only by their 5'/3' orientation. The masses of the w-ion series summarized in table 3, particularly $\mathrm{w}_{9}^{-}$and $\mathrm{w}_{6}^{-}$, allow to differentiate the two strands (Table3). Although this $5{ }^{\prime} / 3^{\prime}$ attribution logically results from peak attribution, this is, to our knowledge, the first example shown for this kind of determination.
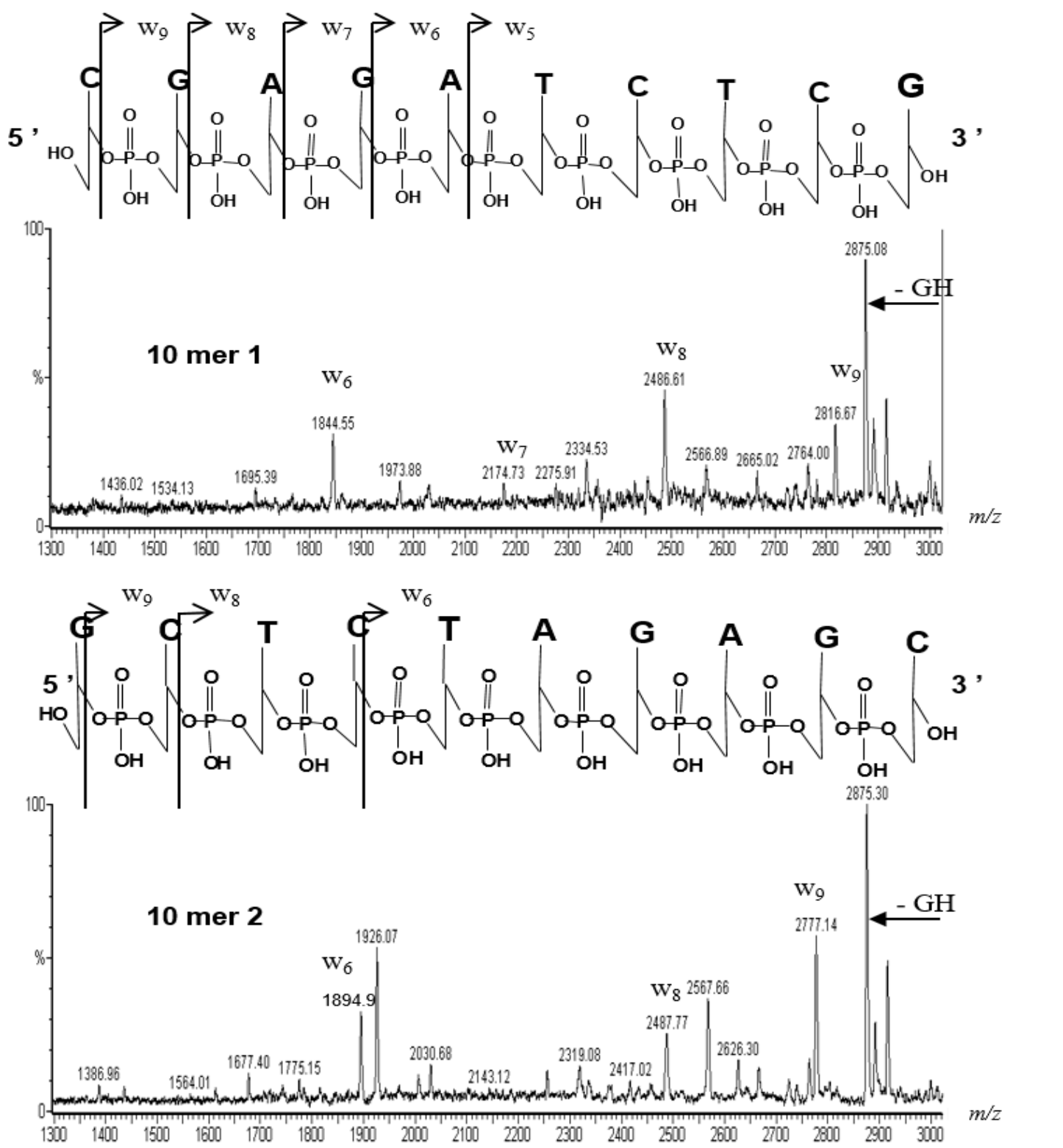

Figure 6. Negative ion MALDI PSD mass spectra of 10mer1 and 10mer 2 (1/1 molar ratio of 2,4,6-

THAP and triammonium citrate, and a $10 \mathrm{pmoL} / \mu \mathrm{L}$ solution of ODN). 
Table 2. PSD fragments of 7 mer and A-deleted 7 mer.

\begin{tabular}{|c|c|c|c|}
\hline & Attribution & $\begin{array}{c}\text { Theoretical } \\
\text { mass } \\
\text { (Da) }\end{array}$ & $\begin{array}{c}\text { Mass } \\
\text { deviation } \\
\text { (Da) }\end{array}$ \\
\hline \multirow[t]{7}{*}{$7 \mathrm{mer}$} & $1959.6[\mathrm{M}-\mathrm{H}]^{-}-\mathrm{GH}$ & 1960.3 & 0.7 \\
\hline & $1861.1 \mathrm{~W}^{-}$ & 1860.2 & -0.9 \\
\hline & $1652.6\left[\mathrm{a}_{6}-\mathrm{AH}-2 \mathrm{H}\right]^{-}$ & 1652.1 & -0.5 \\
\hline & $1556.6 \mathrm{w}_{5}^{-}$ & 1556.0 & -0.6 \\
\hline & 1403.6 unattributed & & \\
\hline & $1243.4 \mathrm{~W}_{4}^{-}$ & 1242.8 & -0.6 \\
\hline & $938.8 \mathrm{~W}_{3}^{-}$ & 938.6 & -0.2 \\
\hline A-deleted 7mer & $1645.7\left[\mathrm{M}^{*}-\mathrm{H}\right]^{-}-\mathrm{GH}$ & 1647.1 & 1.4 \\
\hline \multirow[t]{3}{*}{$\left(M^{*}=M-313.2\right)$} & $1547.9 \mathrm{w}^{*} 6^{-}$ & 1547.0 & -0.9 \\
\hline & $1244.0 w^{*} 5^{-}$ & 1242.8 & -1.2 \\
\hline & $930.5 \mathrm{w}^{*}{ }^{-}$ & 929.6 & -0.9 \\
\hline
\end{tabular}

Note that the mass deviations between measured and theoretical masses range from -0.9 Da to 2.0 Da which is typical of external calibration. In fact, prior calibration with an external standard is mandatory for PSD acquisition, as in the process usually used on commercial instruments only one parent ion is selected at a time. Once two fragment ions per reflectron stage have been unambiguously identified, an internal calibration can then be used to attribute other peaks. Following this procedure, three intense fragment ions remained non-attributed such as $m / z 1926.1$ and $m / z 2567.7$ in the PSD mass spectrum of 10 mer2 and $\mathrm{m} / \mathrm{z} 1403.6$ in the PSD mass spectrum of the 7 mer. Research on sequence dependent fragmentation processes are currently underway in our laboratory.

In spite of these few remaining uncertainties, and the low mass accuracy, the sequence information sought for the 7 mer and 10 mers comes through clearly as the w-ions series can be unambiguously attributed 
from the easily differentiated mass shifts of the four monomers. In fact, the first w-ion of a series will show a mass difference with the $[\mathrm{M}-\mathrm{H}]^{-}$parent ion of an 3'OH terminated ODN of either 208.2 Da (C), 223.2 Da (T), $232.2(\mathrm{~A})$ or $248.2(\mathrm{G})$. Then the mass shifts to be looked for between two consecutive wions are the same as for "ladder" mixtures. The lowest mass difference is $9 \mathrm{Da}$. The information is obtained here more in a "top-down" manner, rather than a forward approach (from $\mathrm{w}_{1}$ upwards), as suggested by Ni et $a l .{ }^{21}$ in their study using electrospray tandem mass spectrometry.

\section{Conclusions}

A mixture of 2,4,6 THAP in acetonitrile and aqueous triammonium citrate solution in a 1:1 molar proportion was found to be a good matrix for the detection of ODN samples. The 33\% proportion of volatile acetonitrile as well as the high salt content ensures fast co-crystallization of the matrix, co-matrix and analyte molecules. MALDI mass spectra obtained from targets prepared with this protocol show intense $[\mathrm{M}-\mathrm{H}]^{-}$ions even when up to $50 \mathrm{mM}$ of sodium chloride is present in the sample, and simple mass spectrum in the low mass range allows the analysis of modified single nucleotide, even as sodium salts. PSD mass spectra can also be obtained from the same targets by increasing the laser fluence.

The high or lower mass accuracy that results from the calibration method, with internal or external standards can be chosen depending on the type of information sought. In the case of "ladder" mixtures or PSD w-ion series, a 1 Da mass accuracy can be enough to derive simple sequence information such as the identity and localisation of a deleted base or the $5^{\prime} / 3^{\prime}$ orientation of a single strand.

\section{Acknowledgments}

The authors wish to thank A. Gautier and S. Piettre from the LFAOC of the University of Rouen, for providing the modified mononucleotides 


\section{References}

1. Koomen JM, Russell WK, Tichy SE, Russell DH. J. Mass Spectrom. 2002; 37: 357-371.

2. Limbach PA. Mass Spectrom. Rev. 1996; 15: 297-336.

3. Nordhoff E, Kirpekar F, Roepstorff P. Mass Spectrom. Rev. 1996; 15: 67-138.

4. Adams MD, Fields C, Venter JC. Automated DNA Sequencing and Analysis. 1998; Academic Press, London.

5. Langley GJ, Herniman JM, Davies NL, Brown T. Rap. Commun. Mass Spectrom. 1999; 13: 1717 1723.

6. Rosey MT, Juhasz P, Smirnov IP, Takach EJ, Martin SA, Haff LA. Proc. Natl. Acad. Sci. USA. 1996; 93: 4724-4729.

7. Vandell VE, Limbach PA. Rap. Commun. Mass Spectrom. 1999; 13: 2014-2021.

8. Asara JM, Allison J. Anal. Chem. 1999; 71: 2866-2870.

9. Deroussent A, Le Caer J-P, Rossier J, Gouyette A. Rap. Commun. Mass Spectrom. 1995; 9: 1-4.

10. Ragas JA, Simmons TA, Limbach PA. The Analyst. 2000; 125: 575-581.

11. Wu K, Steding A, Becker CH. Rap. Commun. Mass Spectrom. 1993; 7: 142-146.

12. Lecchi P, Pannell LK. J. Am. Soc. Mass Spectrom. 1995; 6: 972-975.

13. Lin S, Cotter RJ, Woods AS. Proteins: Structure, Function, and Genetics. 1998; Suppl. 2: 12-21.

14. Kirpekar F, Berkenkamp S, Hillenkamp F. Anal. Chem. 1999; 71: 2334-2339.

15. Zhang L-K, Gross ML. J. Am. Soc. Mass Spectrom. 2000; 11: 854-865.

16. Zhu YF, Chung CN, Taranenko NI, Allman SL, Martin SA, Haff L, Chen CH. Rap. Commun. Mass Spectrom. 1996; 10: 383-388.

17. Koomen JM, Russell WK, Hettick JM, Russell DH. Anal. Chem. 2000; 72: 3860-3866.

18. Figueroa ID, Torres O, Russell DH. Anal. Chem. 1998; 70: 4527-4533.

19. Kaufmann R, Chaurand P, Kirsch D, Spengler B. Rap. Commun. Mass Spectrom. 1996; 10: 11991208.

20. McLuckey SA, Van Berkel GJ, Glish GL. J. Am. Soc. Mass Spectrom. 1992; 3: 60-70.

21. Ni J, Pomerantz SC, Rozenski J, Zhang Y, McCloskey JA. Anal. Chem. 1996; 68: 1989-1999. 